\title{
Antibody Microarrays: Promises and Problems
}

\author{
Wlad Kusnezow and Jörg D. Hoheisel \\ Functional Genome Analysis, Deutsches Krebsforschungszentrum, Heidelberg, Germany
}

BioTechniques 33:S14-S23 (December 2002)

\begin{abstract}
Antibody microarrays have enormous potential for becoming a tool that will allow, at the protein level, the type of global characterization of molecular mixtures that DNA microarrays already make possible at the RNA and $D N A$ level. However, the much higher complexity of proteins both in terms of their sheer number and their structural and biochemical diversity necessitates an even more sophisticated analysis process. Its eventual realization will be demanding to achieve and requires further developments on many technical aspects, not in the least because the understanding of proteins is still comparatively less comprehensive than that of nucleic acids prior to the emergence of array technologies.
\end{abstract}

\section{INTRODUCTION}

As an immediate consequence of the large-scale genomic sequencing efforts, a strong interest has emerged in analyzing the function of the DNA-encoded information on a similarly global scale. However, many aspects of modulation and regulation of cellular activity cannot be investigated on the level of nucleic acids, but require an analysis of the proteome. Several studies in yeast $(31,35,50)$ and higher eukaryots $(2,60)$, for example, demonstrated a poor correlation of mRNA and protein level. This is due to posttranscriptional control of protein translation (69), a number of posttranslational modifications of protein (80), as well as protein degradation by proteolysis $(54,68)$. While posttranscriptional control probably affects only a small number of proteins $(50,54,68)$, recent estimations suggest that there are more than 200 types of protein modification (71). The proportion and importance of protein modification is reflected by the fact that $5 \%-10 \%$ of mammalian genes code for proteins that modify other proteins $(12,58,72)$. Consequently, the complexity in the human proteome is expected to range from 100000 to several million different protein molecules $(12,58,72)$, in striking contrast to the estimated 32000 or so genes $(57,105)$. With respect to data interpretation, the situation is additionally complicated by the fact that no function is known for more than $75 \%$ of the predict- ed proteins of multicellular organisms (20) and that the dynamic range of protein expression can be as large as $10^{7}(54,79)$.

All this has led to a strong demand for analysis procedures on the protein level that correspond in performance to the kind of studies possible on DNA microarrays. Knowledge of genomic sequences and transcriptional profiles do not allow a reliable description of actual protein expression, let alone an examination of protein-protein interaction or prediction of the protein's biochemical activities $(19,21)$. This kind of information, however, is important for a molecular characterization of physiological or developmental cellular stages and has a broad biotechnical and medical potential. Protein microarray technology represents a promising tool to such ends. The increasing interest in this methodology and the kind of information that it will provide is reflected by the number of new journals dedicated to proteome research (58). Also, there is an increasing awareness of the commercial potential. The most optimistic forecasts predicted a business growth in this area from US\$963 million in 2000 to approximately US\$5.6 billion in 2006 (http://www.genomeweb. $\mathrm{com} /$ articles/view-article.asp?Article=20018156158). In the same period, sales in the protein microarray market are estimated to increase tenfold reaching an estimated US\$500 million in 2006 (http://www.chireports.com/pressrelease/prochips.asp).

\section{LARGE-SCALE PROTEIN PROFILING}

The current gold standard for the elucidation of global variations in the expression of proteins is still 2-dimensional gel electrophoresis $(40,61,77)$. However, this procedure is time-consuming and expensive. Also, reproducibility is problematic, even though precast gels and commonly used reagents, protocols, and hardware components have led to improved performance (63). Even in combination with mass spectrometry, only the more abundant proteins can be detected $(33,97)$, thus indicating the need for new technologies (38).

Gygi et al. (34) described a process of protein quantification within complex mixtures, which is based on a so-called isotope- 
coded affinity tag (ICAT) reagent. The ICAT reagent consists of sulfhydryl reactive groups, a deuterated linker, and a biotin tag. Cysteinyl residues in two protein samples are reduced and derivatized with the isotopically light or heavy form of the ICAT reagent, respectively. Both samples are then digested, and tagged peptides are isolated using avidin affinity chromatography. Finally, the isolated peptides are separated and analyzed by microcapillary liquid chromatography and mass spectrometry. This technology enables quantitative measurements on proteins of high and low abundance.

The reverse-phase ProteinChip ${ }^{\circledR}$ is another approach (Ciphergen Biosystems, Fremont, CA, USA). Different surfaces are used to absorb proteins by a variety of noncovalent interactions (67). These chip surfaces select for hydrophobic, electrostatic, or metal affinity binding of proteins, thereby reducing significantly the complexity of the protein population. In a second step, the bound proteins are analyzed by surface-enhanced laser desorption-ionization (SELDI) mass spectrometry, which is a method that is frequently used for protein profiling (26). Accuracy of measurement is high, and even small changes in protein mass, due to glycosylation or phosphorylation, for example, can be identified. In a recent publication (82), patient-matched normal, premalignant, malignant, and metastatic cell populations were microdissected from human esophageal, prostate, breast, ovary, colon, and hepatic tissue sections. Reproducible protein profiles could be obtained from as few as 25 cells. However, the approach has limitations with respect to global protein profiling. Only relatively few and only specific subgroups of proteins are analyzed at a time. Also, prior protein separation is required, because of the domination of highly abundant proteins in mass spectrometry profiles.

Protein microarray technology, finally, could be an attractive tool for protein profiling $(55,67,100)$, the analysis of proteinprotein interactions $(103,110)$, high-throughput screening of protein enzymatic activities $(110,111)$, and even diagnostics (12). Antibody arrays form a special, and to some degree simple, subgroup of protein arrays, for the structural and functional similarity of the applied sensor molecules. In the following, we focus on the application of protein and especially antibody microarray technology as an equivalent on the protein level to RNA profiling on DNA microarrays.

\section{PROTEOMICS COMES TO THE SURFACE}

\section{From Microtiter Plates and Filter Arrays}

The theoretical background for microarray-based ligandbinding assays was developed by Ekins et al. in the late 1980s (22-24,101). According to the model of an ambient analyte assay, antibody microarrays not only permit simultaneous screening of an analyte panel, but should also be more sensitive and rapid as conventional screening systems. Even though the potential of multianalyte microspot analysis was apparent and demonstrated early on, the interest in screening large protein sets only arose as a result of the achievements in genomics.

The first array approaches were attempts to miniaturize biochemical and immunological assays usually performed in 96well microtiter plates $(25,58,106)$. Mendoza et al. $(70)$ created antibody arrays consisting of 96 wells, with 144 elements each for standard enzyme-linked immunosorbent assays (ELISAs). Similar arrays with 64 elements per well were applied to measure prostate-specific antigen (PSA) in human serum samples (108). Mini-arrays of 9 elements were used to screen cytokines with a sensitivity of $1 \mathrm{pg} / \mathrm{mL}$ in different biological samples (73).

Another trend in the initial development phase was the use of filter membranes as array support because of their superior protein binding capacity. Mostly, they were probed with antibodies using ELISA techniques. Maintaining the footprint of the 96well microtiter plate, Ge (29) developed low-density protein arrays, for instance, which contained 48 purified proteins that are primarily involved in transcription for the investigation of specific interactions of proteins with radioactive-labeled DNA, RNA, ligands, and other small chemicals. Huang et al. detected cytokines in patient sera, and cell culture media derived from human glioblastoma cell lines stimulated with recombinant tumor necrosis factor (rTNF) $\alpha(48,49)$. Bussow et al. (10) developed a membrane-based high-density antigen array for the purpose of screening a human fetal brain cDNA expression library of 37830 clones. Purified proteins were deposited onto polyvinylidene difluoride (PVDF) membranes at a density of $300 \mathrm{samples} / \mathrm{cm}^{2}$ (65). Detection threshold of this approach was $10 \mathrm{amol} / \mathrm{nL}$ of spotted protein solution. De Wildt et al. (18) took a reverse approach by spotting 18342 bacterial clones, each one expressing a different single-chain antibody. This technique was developed for the identification of recombinant antibodies that bind with high affinity to selected antigens. Since living cells were spotted that produce large amounts of recombinant antibody, high sensitivity was achieved. Limitations of all filter arrays are the still relatively low resolution and the considerable background. Hence, it is difficult to use them in applications with limiting sample quantities such as protein expression profiling of tumor biopsies.

\section{Protein Arrays on Glass Support}

The first strategies for fabricating protein arrays on glass were developed in the group of Mirzabekov $(3,32,104)$. Arrays were produced by immobilizing proteins in tiny gel pockets that were attached to the glass surface. Different immunoassays, antigen detection, and detection of enzymatic activity were carried out. Because of the 3-dimensional matrix structure, protein immobilization was very efficient. The homogeneously aqueous environment reduced protein denaturation. Disadvantages of the gel pads are the complicated fabrication and the difficulty to recover molecules from the gel, thereby increasing background.

Using robotic instrumentation adapted from the production of cDNA microarrays, MacBeath and Schreiber (66) described a fabrication strategy that opened perspectives for potentially simple large-scale protein analysis. Proteins were spotted on a glass surface coated with either aldehyde-containing silane or a cross-linking reagent that reacts with primary amines. A single spot of the FKBP12-rapamycin binding protein could be identified within an array of 10000 spots of different proteins. This strategy was used to screen protein-protein and protein-ligand interactions and for the identification of specific substrates of several protein kinases.

Haab et al. (36) developed antibody-antigen microarrays on poly-L-lysine coated glass slides. Protein mixtures were labeled with the dyes $\mathrm{Cy}^{\mathrm{TM}} 5$ and $\mathrm{Cy} 3$ (Amersham Biosciences, Piscat- 
away, NJ, USA), respectively, which are also used in many DNA array experiments. However, of the 115 tested antibody-antigen pairs, only $50 \%$ of the antigens and $20 \%$ of the arrayed antibodies provided specific and accurate results. Antibody-antigen interactions could be detected at concentrations as low as 1 $\mathrm{ng} / \mathrm{mL}$. Such arrays can be produced using many protocols and the instrumentation and software tools that already exist for DNA microarrays, thus facilitating preparation, processing, and data evaluation. However, the much higher complexity of the protein population represents a challenge nevertheless, which requires many novel technical solutions.

\section{TECHNICAL ASPECTS OF ANTIBODY MICROARRAY PRODUCTION}

The generation of antibody microarrays is complicated by several common biophysical and chemical properties of proteins:

- There is no simple method of protein amplification such as PCR for nucleic acids.

- Proteins are chemically and structurally much more complex and heterogeneous than mRNA and DNA (40). Therefore, it is difficult to define general protein detection and immobilization strategies that do not discriminate between proteins.

- In contrast to DNA, proteins easily lose their biochemical activity due to denaturation, dehydration, or oxidation. Furthermore, more than $50 \%$ are insoluble or unstable in structure (15).

- The detection of proteins by antibody-antigen interactions is characterized by a broad range of specificity and affinity. Also, it is difficult to obtain a large set of highly specific antibody molecules.

Despite the promises of investigating the proteome by antibody microarrays, there are few in-depth studies about these important parameters. Aiming at a simultaneous analysis with very high sensitivity and specificity of several thousand cellular proteins from biological samples, antibody microarray techniques are still in an early stage of development. Numerous technical difficulties need to be solved and procedures need to be improved in order to establish protein microarrays as a reliable tool in proteomics.

\section{Choice of Sensor Molecule}

To date, most antibody microarrays were produced with several dozen or a few hundred commercially available poly- or monoclonal antibodies. Already in financial terms, however, the generation of such antibody microarrays is an expensive endeavour, made worse by the fact that, currently, only relatively large amounts of individual antibodies are delivered by the suppliers, usually between 0.1 and $2 \mathrm{mg}$. In our hands, between 3000 and 4000 spots could be produced from only $8 \mu \mathrm{g}$ of antibody. Consequently, most antibody is wasted. In the future, antibody suppliers might provide large sets of antibodies, with only small amounts of each molecule, similar to the current trend in oligonucleotide services.

Although several tens of thousands of antibodies are commercially available, this number is insufficient. First and foremost, for many proteins, there are no available antibodies. Also, the number of sensor molecules required for analysis is bigger than the mere number of analytes. In many cases, receptors with different equilibrium dissociation constants and specific to different epitopes are needed for each protein target (41). Therefore, mass production of antibodies with minimal cross-reactivity represents a most critical bottleneck. Classical strategies of antibody generation by animal immunization seem to be impractical. Recombinant antibody display libraries are more promising $(6,41,95)$. This technique is based on a direct coupling of each binder molecule to its DNA code. Phage display, ribosome display, or mRNA display libraries permit not only the production of high-affinity antibodies $(47,95)$, but also the modulation of antibody affinity and specificity $(43,98,99)$, as well as molecule fusions (4) and even the generation of antibodies with di-, tri, and tetravalences (59). Because of the potentially high affinity and specificity of recombinant antibodies and their smaller molecular weight, which is usually about $30 \mathrm{kDa}$ while native antibodies are about 150 $\mathrm{kDa}$, dense and oriented attachment to support surface is facilitated $(6,16,39)$. In addition, the fusion of mRNA and protein can be utilized for the construction of addressable microarrays (107).

Multiplex screening of phage libraries as a means for higher throughput has been demonstrated (64). Still, the requirement for bacterial host cells limits the extension of phage library complexity. The most complex phage libraries represent about $10^{11}$ to $10^{12}$ different antibodies. Since bacterial cultures grow at a cell density of about $10^{8}$ cells $/ \mathrm{mL}$, some $4 \mathrm{~L}$ are needed for library preparation (89). mRNA (85) and ribosomal display techniques (37) circumvent this problem, since all steps, amplification, transcription, translation, selection, purification, and the maturation of antibody affinity, occur entirely in vitro. Using ribosome display technique, several antibody fragments with affinities in the low picomolar range could be isolated (38). Therefore, the two latter techniques enable the establishment of a complexity beyond that of phage libraries. In addition, the automation of the production processes is facilitated, which will be a major advantage to future antibody engineering $(6,41)$. A widely used means for isolating specific antibodies is the incubation of particular cells or tissue sections with display libraries. However, an inherent drawback of this method is that only binders against more abundant proteins could be isolated so far (46). High-throughput screening based on the in vitro techniques is not developed as extensively yet as the assays with the in vivo phage display system $(41,46)$.

A more recent development in the area of sensor molecules is the engineering of microbial proteins so that they obtain antibody-like properties (56). One of the most promising alternatives is a phage library made of engineered domains of staphylococcus protein A, called affibodies. Each molecule consists of 58 amino acids only (76). This protein has some advantages compared to a classical immunoglobulin (Ig) domain: smaller size means higher stability and enables immobilization at higher concentrations. Similarly to the developments in the field of recombinant antibody engineering, cell-free display systems are being developed (1).

As another option, short single-stranded nucleic acid species with protein binding properties (aptamers) make a strong claim for their use as sensor molecules. Combinatorial aptamer libraries have diversities of $10^{13}-10^{17}$. Using an aptamer-based assay, IgE 
Table 1. Attachment Strategies for Microarray Production

\begin{tabular}{|llc|}
\hline \multicolumn{1}{|c|}{ Surface Chemistry } & \multicolumn{1}{c|}{ Binding Mode } & Reference \\
\hline $\begin{array}{l}\text { Polyacrylamide gel activated by } \\
\text { hydrazide groups }\end{array}$ & Antibody carbohydrate residues oxidized with NalO & $(3)$ \\
Poly-L-lysine & Adsorption & $(36,53,67,86,100)$ \\
Nitrocellulose & Adsorption & $(5,26,53,55,67)$ \\
Cyanosilane (microtiter plate) & Adsorption & $(108)$ \\
Aldehyde silane & Amino groups & $(53,66,67,100,110)$ \\
BSA/bifunctional N-hydroxysuccinimide & Amino groups & $(66)$ \\
Aminosilane/bifunctional & Amino groups & $(70)$ \\
N-hydroxysuccinimide (microtiter plate) & & $(27)$ \\
Hydrogel aldehyde & Amino groups & $(91)$ \\
Mercaptosilane/maleimido- & Amino groups & $(27,111)$ \\
N-hydroxysuccinimide & & $(110)$ \\
Epoxy silane & Amino, thiol, hydroxyl groups & $(88,96)$ \\
Nickel coating & His-tag & $(62)$ \\
Neutravidin & Biotinylated antibodies & \\
Avidin & Biotinylated intenein tag of proteins & \\
\hline
\end{tabular}

could be detected with extraordinary sensitivity at a level of 37 zmol and a dynamic range of $10^{5}$ (45). Aptamer microarrays could be constructed using microarray surfaces for DNA attachment or even synthesized in situ (51). In an aptamer microarray scenario, aptamer-ligand complexes will be photo-crosslinked and subsequently washed at high stringency for the reduction of nonspecific binding and background $(8,45)$. However, there are some problematic issues, too. Because of the low chemical diversity of aptamers, 4 nucleotides versus 20 amino acids, ligand binding by aptamers may be dominated by electrostatic interactions resulting in high strength but still low specificity of such interactions (51). Additionally, aptamers are susceptible to nucleases, which could be present in the analyzed protein mixtures.

\section{Antibody Immobilization}

The solid support has profound consequences on the quality of microarray analyses (11), since it influences not only the efficiency of antibody attachment, but also the degree of nonspecific binding, for example, and the accessibility of the antibodies to the antigens, which differ widely in structure. Frequently used glass modifications, such as aldehyde activation or coating with polyL-lysine or nitrocellulose, are surfaces typical for the attachment of DNA. This reflects the fact that protein microarrays were mostly developed in laboratories that worked on DNA microarrays before. The classical protein or peptide immobilization chemistry, however, offers a multitude of well-established and relatively simple protein attachment strategies on glass support $(11,74,102)$, which are bound to improve the performance of antibody array significantly (Kusnezow et al., unpublished data). While it is difficult to define general immobilization strategies that do not discriminate between proteins, the structural similarity of antibodies mollifies this aspect. In Table 1, various procedures are listed that were found to be suitable to glass slide modification.

In principle, oriented attachment is a preferable immobiliza- tion strategy. The antibodies' active sites are better accessible, and also their stability is improved (102). Therefore, antibodies are often immobilized via their carbohydrate moieties to hydrazide derivatives or via thiol groups at the hinge region to maleimide derivatives $(14,75,87,94)$. In all cases, higher signal intensities could be obtained compared to random attachment (3). However, both strategies require antibody activation, additional purification steps, and subsequent control of antibody concentration (44). This may prove incompatible with practical applications, during which large numbers of expensive and sometimes rather unique molecules are managed. First, the treatment and subsequent purification of very small antibody quantities may lead to significant losses (94). Second, the antibodies have to be activated directly prior to spotting, but cannot be kept in this state for a long time, wasting valuable resources. In addition, some monoclonal antibodies do not have carbohydrate residues. For these reasons, random attachment procedure could well be superior. The highly reactive epoxysilane surface, for example, reacts not only with amino groups, but also with other nucleophils on the protein surface like alcohol, thiol, and acid groups (84), exhibiting a high binding capacity (111).

While directed attachment for a collection of native proteins is not a trivial issue, expression libraries of recombinant fusion proteins offer better opportunities. Zhu et al. produced fusion proteins with glutathione-S-transferase and $\mathrm{His}_{6}$ tag (110) and spotted them at high density on functionalized glass slides. In vitro protein expression of His-tag fusion proteins and preparation of protein in situ arrays (PISAs) (42) may offer another option. In comparison to aldehyde slides, site-specific attachment on nickel-coated slides demonstrated superior signal intensity. However, the stability of the complex depends on $\mathrm{pH}$, a fact that can make application rather difficult (78). To overcome this, Lesaicherre et al. proposed a new strategy for a site-directed attachment of fusion protein (62). Fusion proteins containing an intein-tag with chitin-binding domain were purified on 
Table 2. Selection of Commercial Suppliers of Products and Services Related to Antibody Microarrays

\begin{tabular}{|c|c|c|}
\hline Company Name & Products and Services & URL \\
\hline Accelr8 Technology Corporation & Slides, detection technology & http:// www.accelr8.com/ \\
\hline Advanced Array Technology & S.A. Slides & http://www.aat-array.com/ \\
\hline Amersham Pharmacia Biotech & Microarray supplies, dyes, spotters & http://www.apbiotech.com/ \\
\hline Aspira Biosystems & Artificial antibody technology & http://www.aspirabio.com/ \\
\hline BD Biosciences Clontech & Antibody microarray kit & http://www.clontech.com/ \\
\hline Biolnsights & Biotechnology consulting & http://www.bioinsights.net/ \\
\hline Denovo Biolabels & Dyes & http://www.biolabels.com/ \\
\hline Exiqon & Slides & http://www.exiqon.com/ \\
\hline HTS Biosystems & Complete microarray systems & http://www.htsbiosystems.com/ \\
\hline Hypromatrix & Antibody microarrays, antibodies & http://www.hypromatrix.com/ \\
\hline Meso Scale Discovery & Microtiter plate-based array technology & http://www.meso-scale.com \\
\hline Nextgensciences & Protein array workstation & http://www.nextgensciences.com/ \\
\hline NoAb BioDiscoveries & Slides & http://www.noabbiodiscoveries.com/ \\
\hline PerkinEImer Life Sciences & Arrayer, slides, protein array workstation & http://lifesciences.perkinelmer.com/ \\
\hline Pierce Boston Technology Center & Customized arrays in microtiter plates & http://www.piercebtc.com/ \\
\hline Prolinx & Polymeric array surface system & http://www.prolinx.com/ \\
\hline Quantifoil & Slides & http://www.quantifoil.com/ \\
\hline Scandinavian Micro Biodevices & Slides & http://www.smb.dk/ \\
\hline Schleicher \& Schuell BioScience & Slides & http://www.s-und-s.de/ \\
\hline TeleChem International & Slides, spotting buffer & http://arrayit.com/ \\
\hline XanTec & Slides & http://www.xantec.com/ \\
\hline Xenopore & Slides & http://www.xenopore.com/ \\
\hline
\end{tabular}

columns filled with chitin beads and biotinylated cysteine. Disruption of the protein-intein connection produced biotinylated proteins, which were spotted on avidin-coated slides. Also, other procedures were reported such as the generation of libraries of antibodies fused to a maltose-binding protein (4).

The ability to protect antibodies against denaturation during microarray production is yet another important technical aspect. Frequently, glycerol is added to the spotting solution to prevent antibody dehydration and subsequent denaturation $(53,66)$. In our experience (unpublished results), addition of disaccharides, which are often used as protective reagent in lyophilization processes (17), improved antibody stability significantly.

Proper storage of slides after spotting the antibodies is an important time- and material-saving element. It allows bulk production of slides and their subsequent continuous consumption. Sreekumar et al. stored spotted slides in humid chambers for up to 1 month. Still, they report that the antibody stability decreased slightly during this period (100). Since a high moisture level affects the chemical stability of proteins (7), lyophilization or frozen storage are superior procedures.

\section{Signal Detection and Sensitivity}

About $90 \%$ of proteins make up only $10 \%$ of the total protein mass (72). Additionally, many disease relevant proteins are present with only a few molecules per cell. Expression levels vary within 5 to 6 orders of magnitude in different biological samples, as known for interleukin (IL)-4 cytokine for example, which is implicated in allergy, autocrine tumor growth, and susceptibility to some infectious diseases. In view of this, the sensitivity of antibody microarrays should be at least in the picogram range. Under the condition that the immunoassay does not influence the initial analyte concentration, theory suggests a detection limit of antibody microarrays of approximately $10^{-17} \mathrm{M}$

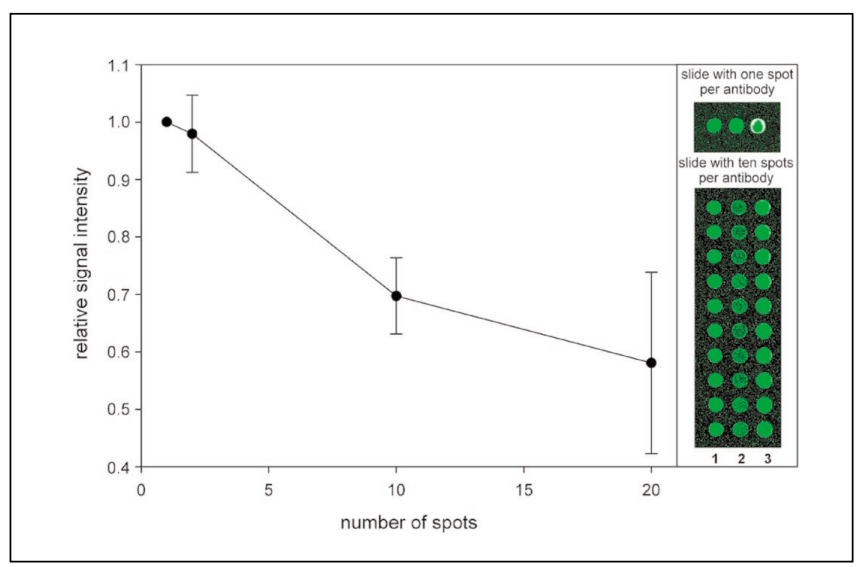

Figure 1. Dependency of signal intensities on the number of reactive antibody spots at conditions under which target depletion could take place. 
(24). Such high sensitivity, however, could require relatively large sample volumes. On antibodies with an affinity constant of $10^{10}$ $\mathrm{L} / \mathrm{mol}$, the sample volume should be at least $4 \mathrm{~mL}$, for instance. Such a volume is imaginable only for few experimental systems like protein profiling of cell lines. Silzel et al. (96), on the other hand, described a microarray analysis performed outside ambient analyte conditions. Using antibodies against different IgG subclasses, a competitive reduction of signal intensities was seen under those conditions upon the addition of spots with antibody molecules that recognized total IgG. Similar results could be obtained with different systems, also, even at analyte concentrations that resemble ambient conditions more closely (Figure 1). Apart from the influence of antibody concentration and sample volume, one would, therefore, expect antibodies of low specificity to affect the overall result by binding several antigens.

While a small spot area is advantageous overall, reduction beyond a certain limit may actually influence sensitivity negatively. This limit is set by the detection method and its resolution. The number of individual scores needs to be big enough to discriminate signal from the intrinsic experimental variation. Most published antibody microarray systems report a detection limit in the nanogram range. Possibly, the most frequent approach is the detection of the bound target with a second labeled capture molecule in a sandwich assay format. On microarrays, a comparable or even better sensitivity was obtained than in conventional ELISA assays, the detection limit with complex biological samples being about $10 \mathrm{ng} / \mathrm{mL}(53,55,70)$. Taking advantage of a highly efficient antibody coupling strategy $(28,108)$, PSA in serum could be detected at a concentration of $200 \mathrm{pg} / \mathrm{mL}$. Using ELISA signal amplification systems (73), sensitivities of down to $1 \mathrm{pg} / \mathrm{mL}$ were achieved. However, application of ELISA detection limits the degree of multiplexing (73). Also, the dynamic range is usually only of about two orders of magnitude $(73,108)$. Fluorescently labeled secondary antibodies $(88)$ may provide the means for a more sensitive sandwich technique.

As an alternative, the rolling circle DNA amplification (RCA) method was adapted to the detection of antigens by Schweitzer et al. $(90,92)$. In the presence of a primer, which is attached to a secondary antibody, DNA polymerase, and nucleotides, amplification of circular DNA occurs, resulting in a long DNA molecule, which contains hundreds of copies of the circular template molecule. ImmunoRCA could yield sufficiently higher sensitivities than classical detection methods, with a dynamic range of up to four orders of magnitude (92). In an initial experiment, human purified PSA could be detected on microarray slides at a level of $100 \mathrm{fg} / \mathrm{mL}$ (92). ImmunoRCA detection applied to an array of 75 cytokine antibodies resulted in the following sensitivities: $29 \%$ of the cytokine features had a sensitivity of less than $100 \mathrm{pg} / \mathrm{mL}, 60 \%$ of less than $10 \mathrm{pg} / \mathrm{mL}$, and $11 \%$ of less than $1 \mathrm{pg} / \mathrm{mL}$ (91). IgE concentration in blood serum could be detected at $1 \mathrm{pg} / \mathrm{mL}$ (109). While sandwich techniques are suitable for some diagnostic purposes $(53,88)$, these methods may be difficult to apply to large-scale protein profiling, because of the processing that is required (52).

Detection of analyte by direct fluorescence labeling produces a larger dynamic range and is simpler to perform (96) but is still not as sensitive as immunoRCA (91). Sample labeling with fluorophors, similar to the procedure that is routinely used for transcriptional profiling on cDNA microarrays, is well suited for pro- tein profiling on antibody microarrays $(36,100)$. Detection limits of $1 \mathrm{pg} / \mathrm{mL}$ could be achieved in our laboratory when incubating antibody slides with a couple of labeled antigens, while 100 $\mathrm{pg} / \mathrm{mL}$ was possible with complex protein samples. However, direct labeling has also its drawbacks. Covalent attachment of fluorophors decreases the solubility of proteins (81), for example. Too high a degree of label incorporation can also interfere with the antigen-antibody recognition. Both factors may adversely influence signal intensity as well as background. In addition, the extent of labeling depends on the kind of protein, its concentration in the analyzed sample, and the type of fluorophor. Consequently, the test and control sample should both be labeled with either fluorophor and analyzed in reciprocal incubations.

\section{CURRENT AND FUTURE MULTITARGET DISCOVERY AND DIAGNOSTICS}

A cheap and fast proteome profiling would accelerate the identification of drug targets and disease markers. However, while protein microarray technology overall has been very successful already in demonstrating its usefulness to large-scale analyses of protein-protein interaction $(26,103,110)$ and the investigation of enzymatic activity $(110,111)$, the performance of antibody microarrays in protein profiling has only been moderately productive. The following reports reflect the current status.

Knezevic et al. (55) analyzed protein expression in squamous cell carcinoma of the oral cavity. In total, 368 antibodies were spotted on nitrocellulose-coated glass slides. Laser capture microdissection (LCM) and ELISA-like detection were used for the preparation and analysis of clinical samples. With only 0.5 $\mu \mathrm{g}$ protein available for each microarray incubation, 11 proteins were found to have a different expression level in either epithelium or stroma in the vicinity of the cancer cells. However, no real quantification was performed.

Sreekumar et al. (100) used microarrays with 146 antibodies on aldehyde slides and labeling with $\mathrm{Cy} 3$ or $\mathrm{Cy} 5$, respectively, to detect protein level alterations in a colon carcinoma line that had been treated with ionizing radiation. Radiation-induced upand down-regulation was demonstrated for several apoptotic regulators. Unfortunately, only the data obtained with 20 of the 146 antibodies were presented in this publication.

Schweitzer et al. applied immunoRCA detection to a microarray of 51 cytokine-specific antibodies to measure cytokine secretion of dendritic cells upon stimulation with lipopolysaccharide or TNF (91). The microarrays were printed on activated glass slides that had been coated with thiolsilane and bifunctional crosslinker molecules. Each slide was divided by Teflon ${ }^{\circledR}$ boundaries in 16 circular analysis sites that contained 256 features each. This layout allowed the parallel processing of several $10-\mu \mathrm{L}$ samples. This study revealed that about one-third of the cytokines represented on the microarray increased their expression level by at least 4-fold upon stimulation of the cells. Some quantitative expression profiles were in agreement with data that had been obtained earlier by other means, but also several new cytokines were found that varied in their expression levels.

While to date the last study seems to be the most successful one, it is very difficult to compare the performance of the various systems, because of the many experimental differences. Also, 
the complexity of the protein samples differs, with the microdissected tumor cells being more difficult to analyze, compared to the secreted proteins in the last study. In any case, however, comprehensive analyses as done nowadays on the level of transcripts are still some distance away and will require a multidisciplinary effort for their establishment, a fact which is typical for proteome research as a whole (http://www.genomeweb.com/ articles/view-article. asp?Article=2001108222320).

In addition to the application of antibody microarrays to the profiling of protein levels, many other potential applications do exist. One example is the investigation of antigens on the cell surface. Belov et al. (5) developed an antibody microarray to characterize the expression of surface antigens on leukocytes and leukemia cells. A suspension of unlabeled leukocytes isolated from peripheral blood of patients with chronic lymphocytic leukemia, hairy cell leukemia, mantle cell lymphoma, acute myeloid leukemia and T-cell acute lymphoblastic leukemia was applied to an array that contained 60 specific antibodies. The resulting patterns were highly characteristic for each hematologic malignancy. This type of antibody array allows a rapid and sensitive immunophenotyping that could be performed in a clinical setting. Also, arrays of living cells (25) could be generated this way, enabling an in situ investigation of various biochemical parameters (112).

Apart from the academic research, quite a few companies are active in this field as well (http://www.functionalgenomics.org. uk/sections/resources/protein_arrays_companies.htm) (Table 2). Examples are the antibody microarrays developed by $B D$ Biosciences Clontech (Palo Alto, CA, USA) and Hypromatrix (Worcester, MA, USA), which contain several hundred antibodies. Others produce platforms for protein profiling (83). There are also many efforts in the development of recombinant antibodies, affibodies, or aptamers for their use as sensor molecules, activities in which an array of companies are involved $(1,9,93)$. Zyomix (Hayward, CA, USA), for example, applies phage display libraries to microarrays at high density. The question may arise if academic science can keep up with the advances made in industry. Some think that industry will be responsible for the major developments in this area in the near future $(1,30,93)$. However, the field is too diverse and complex, and the technology is still in its early stages, which not only gives academic researchers a fair chance of successful contributions but also requires their active participation (13).

\section{REFERENCES}

1.Abbott, A. 2002. Betting on tomorrow's chips. Nature 415:112-114.

2.Anderson, L. and J. Seilhamer. 1997. A comparison of selected mRNA and protein abundances in human liver. Electrophoresis 18:533-537.

3.Arenkov, P., A. Kukhtin, A. Gemmell, S. Voloshchuk, V. Chupeeva, and A. Mirzabekov. 2000. Protein microchips: use for immunoassay and enzymatic reactions. Anal. Biochem. 278:123-131.

4.Bach, H., Y. Mazor, S. Shaky, A. Shoham-Lev, Y. Berdichevsky, D.L. Gutnick, and I. Benhar. 2001. Escherichia coli maltose-binding protein as a molecular chaperone for recombinant intracellular cytoplasmic single-chain antibodies. J. Mol. Biol. 312:79-93.

5.Belov, L., O. de la Vega, C.G. dos Remedios, S.P. Mulligan, and R.I. Christopherson. 2001. Immunophenotyping of leukemias using a cluster of differentiation antibody microarray. Cancer Res. 61:4483-4489.

6.Borrebaeck, C.A. 2000. Antibodies in diagnostics-from immunoassays to protein chips. Immunol. Today 21:379-382.
7.Breen, E.D., J.G. Curley, D.E. Overcashier, C.C. Hsu, and S.J. Shire. 2001. Effect of moisture on the stability of a lyophilized humanized monoclonal antibody formulation. Pharmacol. Res. 18:1345-1353.

8.Brody, E.N. and L. Gold. 2000. Aptamers as therapeutic and diagnostic agents. J. Biotechnol. 74:5-13.

9.Brower, V. 2001. Proteomics: biology in the post-genomic era. Companies all over the world rush to lead the way in the new post-genomics race. EMBO Rep. 2:558-560.

10.Bussow, K., D. Cahill, W. Nietfeld, D. Bancroft, E. Scherzinger, H. Lehrach, and G. Walter. 1998. A method for global protein expression and antibody screening on high-density filters of an arrayed cDNA library. Nucleic Acids Res. 26:5007-5008.

11.Butler, J.E. 2000. Solid supports in enzyme-linked immunosorbent assay and other solid-phase immunoassays. Methods 22:4-23.

12.Cahill, D.J. 2001. Protein and antibody arrays and their medical applications. J. Immunol. Methods 250:81-91.

13.Cahill, M.A. and A. Nordheim. 2001. Proteomics in academic environment, p. 277. In S.P.A.M. Dunn (Ed.), Proteomics from Protein Sequence to Function. BIOS Scientific Publishers Limited, Oxford, UK.

14.Catimel, B., M. Nerrie, F.T. Lee, A.M. Scott, G. Ritter, S. Welt, L.J. Old, A.W. Burgess, and E.C. Nice. 1997. Kinetic analysis of the interaction between the monoclonal antibody A33 and its colonic epithelial antigen by the use of an optical biosensor. A comparison of immobilisation strategies. J. Chromatogr. A 776:15-30.

15.Christendat, D., A. Yee, A. Dharamsi, Y. Kluger, A. Savchenko, J.R. Cort, V. Booth, C.D. Mackereth, et al. 2000. Structural proteomics of an archaeon. Nat. Struct. Biol. 7:903-909.

16.Clarke, W., J.D. Beckwith, A. Jackson, B. Reynolds, E.M. Karle, and D.S. Hage. 2000. Antibody immobilization to high-performance liquid chromatography supports. Characterization of maximum loading capacity for intact immunoglobulin G and Fab fragments. J. Chromatogr. A 888:13-22.

17.Cleland, J.L., X. Lam, B. Kendrick, J. Yang, T.H. Yang, D. Overcashier, D. Brooks, C. Hsu, and J.F. Carpenter. 2001. A specific molar ratio of stabilizer to protein is required for storage stability of a lyophilized monoclonal antibody. J. Pharm. Sci. 90:310-321.

18.de Wildt, R.M., C.R. Mundy, B.D. Gorick, and I.M. Tomlinson. 2000. Antibody arrays for high-throughput screening of antibody-antigen interactions. Nat. Biotechnol. 18:989-994.

19.Dunham, I., N. Shimizu, B.A. Roe, S. Chissoe, A.R. Hunt, J.E. Collins, R. Bruskiewich, D.M. Beare, et al. 1999. The DNA sequence of human chromosome 22. Nature 402:489-495.

20.Edwards, A.M., C.H. Arrowsmith, and B. des Palliers. 2000. Proteomics: new tools for new era. Modern Drug Discovery 5:35-44

21.Eisenberg, D., E.M. Marcotte, I. Xenarios, and T.O. Yeates. 2000. Protein function in the post-genomic era. Nature 405:823-826.

22.Ekins, R. 1990. Measurement of free hormones in blood. Endocr. Rev. 11:546.

23.Ekins, R., F. Chu, and E. Biggart. 1990. Multispot, multianalyte, immunoassay. Ann. Biol. Clin. 48:655-666.

24.Ekins, R.P. 1998. Ligand assays: from electrophoresis to miniaturized microarrays. Clin. Chem. 44:2015-2030.

25.Emili, A.Q. and G. Cagney. 2000. Large-scale functional analysis using peptide or protein arrays. Nat. Biotechnol. 18:393-397.

26.Espejo, A., J. Cote, A. Bednarek, S. Richard, and M.T. Bedford. 2002. A protein-domain microarray identifies novel protein-protein interactions. Biochem. J. 23: [epub ahead of print].

27.Ewart, T., S. Carmichael, R. Shipman, and P.-Y. Wong. 2001. APTarray: a human pathogen microarray for the determination of serum antibody titer. In www.noabdiagnostics.com/technotes/technical\%20Note\%20010907TE. pdf. NoAbBiodiscoveries.

28.Falipou, S., J.M. Chovelon, C. Martelet, J. Margonari, and D. Cathignol. 1999. New use of cyanosilane coupling agent for direct binding of antibodies to silica supports. Physicochemical characterization of molecularly bioengineered layers. Bioconjug. Chem. 10:346-353.

29.Ge, H. 2000. UPA, a universal protein array system for quantitative detection of protein-protein, protein-DNA, protein-RNA and protein-ligand interactions. Nucleic Acids Res. 28:e3.

30.J.S. MacNeil. 2001. Will protein microarrays ever make it to market? GenomeWeb 2001 [3/2/01]

31.Griffin, T.J., S.P. Gygi, T. Ideker, B. Rist, J. Eng, L. Hood, and R. Aebersold. 2002. Complementary profiling of gene expression at the transcriptome and proteome levels in Saccharomyces cerevisiae. Mol. Cell Proteomics 
1:323-333

32.Guschin, D., G. Yershov, A. Zaslavsky, A. Gemmell, V. Shick, D. Proudnikov, P. Arenkov, and A. Mirzabekov. 1997. Manual manufacturing of oligonucleotide, DNA, and protein microchips. Anal. Biochem. 250:203211 .

33.Gygi, S.P., G.L. Corthals, Y. Zhang, Y. Rochon, and R. Aebersold. 2000. Evaluation of two-dimensional gel electrophoresis-based proteome analysis technology. Proc. Natl. Acad. Sci. USA 97:9390-9395.

34.Gygi, S.P., B. Rist, S.A. Gerber, F. Turecek, M.H. Gelb, and R. Aebersold. 1999. Quantitative analysis of complex protein mixtures using isotope-coded affinity tags. Nat. Biotechnol. 17:994-999.

35.Gygi, S.P., Y. Rochon, B.R. Franza, and R. Aebersold. 1999. Correlation between protein and mRNA abundance in yeast. Mol. Cell Biol. 19:17201730 .

36.Haab, B.B., M.J. Dunham, and P.O. Brown. 2001. Protein microarrays for highly parallel detection and quantitation of specific proteins and antibodies in complex solutions. Genome Biol. 2:RESEARCH0004.

37.Hanes, J. and A. Pluckthun. 1997. In vitro selection and evolution of functional proteins by using ribosome display. Proc. Natl. Acad. Sci. USA 94:4937-4942.

38.Hanes, J., C. Schaffitzel, A. Knappik, and A. Pluckthun. 2000. Picomolar affinity antibodies from a fully synthetic naive library selected and evolved by ribosome display. Nat. Biotechnol. 18:1287-1292.

39.Harma, H., P. Tarkkinen, T. Soukka, and T. Lovgren. 2000. Miniature single-particle immunoassay for prostate-specific antigen in serum using recombinant Fab fragments. Clin. Chem. 46:1755-1761.

40.Harry, J.L., M.R. Wilkins, B.R. Herbert, N.H. Packer, A.A. Gooley, and K.L. Williams. 2000. Proteomics: capacity versus utility. Electrophoresis 21:1071-1081.

41.Hayhurst, A. and G. Georgiou. 2001. High-throughput antibody isolation. Curr. Opin. Chem. Biol. 5:683-689.

42.He, M. and M.J. Taussig. 2001. Single step generation of protein arrays from DNA by cell-free expression and in situ immobilisation (PISA method). Nucleic Acids Res. 29:E73-73.

43.Hemminki, A., S. Niemi, L. Hautoniemi, H. Soderlund, and K. Takkinen. 1998. Fine tuning of an anti-testosterone antibody binding site by stepwise optimisation of the CDRs. Immunotechnology 4:59-69.

44.Hermanson, G.T. 1996. Bioconjugate Techniques. Academic Press, New York.

45.Hesselberth, J., M.P. Robertson, S. Jhaveri, and A.D. Ellington. 2000. In vitro selection of nucleic acids for diagnostic applications. J. Biotechnol. 74:15-25.

46.Holt, L.J., C. Enever, R.M. de Wildt, and I.M. Tomlinson. 2000. The use of recombinant antibodies in proteomics. Curr. Opin. Biotechnol. 11:445449

47.Hoogenboom, H.R. and P. Chames. 2000. Natural and designer binding sites made by phage display technology. Immunol. Today 21:371-378.

48.Huang, R.P. 2001. Detection of multiple proteins in an antibody-based protein microarray system. J. Immunol. Methods 255:1-13.

49.Huang, R.P., R. Huang, Y. Fan, and Y. Lin. 2001. Simultaneous detection of multiple cytokines from conditioned media and patient's sera by an antibody-based protein array system. Anal. Biochem. 294:55-62.

50.Ideker, T., V. Thorsson, J.A. Ranish, R. Christmas, J. Buhler, J.K. Eng, R. Bumgarner, D.R. Goodlett, R. Aebersold, and L. Hood. 2001. Integrated genomic and proteomic analyses of a systematically perturbed metabolic network. Science 292:929-934.

51.James, W. 2001. Nucleic acid and polypeptide aptamers: a powerful approach to ligand discovery. Curr. Opin. Pharmacol. 1:540-546.

52.Jenkins, R.E. and S.R. Pennington. 2001. Arrays for protein expression profiling: towards a viable alternative to two-dimensional gel electrophoresis? Proteomics 1:13-29.

53.Joos, T.O., M. Schrenk, P. Hopfl, K. Kroger, U. Chowdhury, D. Stoll, D. Schorner, M. Durr, et al. 2000. A microarray enzyme-linked immunosorbent assay for autoimmune diagnostics. Electrophoresis 21:2641-2650.

54.Kettman, J.R., C. Coleclough, J.R. Frey, and I. Lefkovits. 2002. Clonal proteomics: one gene-family of proteins. Proteomics 2:624-631.

55.Knezevic, V., C. Leethanakul, V.E. Bichsel, J.M. Worth, V.V. Prabhu, J.S. Gutkind, L.A. Liotta, P.J. Munson, E.F. Petricoin 3rd, and D.B. Krizman. 2001. Proteomic profiling of the cancer microenvironment by antibody arrays. Proteomics 1:1271-1278.

56.Kronvall, G. and K. Jonsson. 1999. Receptins: a novel term for an expanding spectrum of natural and engineered microbial proteins with binding properties for mammalian proteins. J. Mol. Recognit. 12:38-44.

57.Lander, E.S., L.M. Linton, B. Birren, C. Nusbaum, M.C. Zody, J. Baldwin K. Devon, K. Dewar, et al. 2001. Initial sequencing and analysis of the human genome. Nature 409:860-921.

58.Laurell, T. and G. Marko-Varga. 2002. Miniaturisation is mandatory unravelling the human proteome. Proteomics 2:345-351.

59.Le Gall, F., S.M. Kipriyanov, G. Moldenhauer, and M. Little. 1999. Ditri- and tetrameric single chain Fv antibody fragments against human CD19: effect of valency on cell binding. FEBS Lett. 453:164-168.

60.Le Naour, F., L. Hohenkirk, A. Grolleau, D.E. Misek, P. Lescure, J.D. Geiger, S. Hanash, and L. Beretta. 2001. Profiling changes in gene expression during differentiation and maturation of monocyte-derived dendritic cells using both oligonucleotide microarrays and proteomics. J. Biol. Chem. 276:17920-17931.

61.Lee, K.H. 2001. Proteomics: a technology-driven and technology-limited discovery science. Trends Biotechnol. 19:217-222.

62.Lesaicherre, M.L., R.Y. Lue, G.Y. Chen, Q. Zhu, and S.Q. Yao. 2002. Intein-mediated biotinylation of proteins and its application in a protein microarray. J. Am. Chem. Soc. 124:8768-8769.

63.Lilley, K.S., A. Razzaq, and P. Dupree. 2002. Two-dimensional gel electrophoresis: recent advances in sample preparation, detection and quantitation. Curr. Opin. Chem. Biol. 6:46-50.

64.Lou, J., R. Marzari, V. Verzillo, F. Ferrero, D. Pak, M. Sheng, C. Yang, D. Sblattero, and A. Bradbury. 2001. Antibodies in haystacks: how selection strategy influences the outcome of selection from molecular diversity libraries. J. Immunol. Methods 253:233-242.

65.Lueking, A., M. Horn, H. Eickhoff, K. Bussow, H. Lehrach, and G. Walter. 1999. Protein microarrays for gene expression and antibody screening. Anal. Biochem. 270:103-111.

66.MacBeath, G. and S.L. Schreiber. 2000. Printing proteins as microarrays for high-throughput function determination. Science 289:1760-1763.

67.Madoz-Gurpide, J., H. Wang, D.E. Misek, F. Brichory, and S.M. Hanash. 2001. Protein based microarrays: a tool for probing the proteome of cancer cells and tissues. Proteomics 1:1279-1287.

68. Marcotte, E.M. 2001. Measuring the dynamics of the proteome. Genome Res. 11:191-193.

69.McCarthy, J.E. 1998. Posttranscriptional control of gene expression in yeast. Microbiol. Mol. Biol. Rev. 62:1492-1553.

70.Mendoza, L.G., P. McQuary, A. Mongan, R. Gangadharan, S. Brignac, and M. Eggers. 1999. High-throughput microarray-based enzyme-linked immunosorbent assay (ELISA). BioTechniques 27:778-788.

71.Meri, S. and M. Baumann. 2001. Proteomics: posttranslational modifications, immune responses and current analytical tools. Biomol. Eng. 18:213220.

72.Miklos, G.L. and R. Maleszka. 2001. Protein functions and biological contexts. Proteomics 1:169-178.

73.Moody, M.D., S.W. Van Arsdell, K.P. Murphy, S.F. Orencole, and C. Burns. 2001. Array-based ELISAs for high-throughput analysis of human cytokines. BioTechniques 31:186-194.

74.Nisnevitch, M. and M.A. Firer. 2001. The solid phase in affinity chromatography: strategies for antibody attachment. J. Biochem. Biophys. Methods 49:467-480.

75.Nisnevitch, M., M. Kolog-Gulco, D. Trombka, B.S. Green, and M.A. Firer 2000. Immobilization of antibodies onto glass wool. J. Chromatogr. B Biomed. Sci. Appl. 738:217-223.

76.Nord, K., E. Gunneriusson, J. Ringdahl, S. Stahl, M. Uhlen, and P.A. Nygren. 1997. Binding proteins selected from combinatorial libraries of an alpha-helical bacterial receptor domain. Nat. Biotechnol. 15:772-777.

77.Oliver, D.J., B. Nikolau, and E.S. Wurtele. 2002. Functional genomics: high-throughput mRNA, protein, and metabolite analyses. Metab. Eng. 4:98-106.

78.Paborsky, L.R., K.E. Dunn, C.S. Gibbs, and J.P. Dougherty. 1996. A nickel chelate microtiter plate assay for six histidine-containing proteins. Anal. Biochem. 234:60-65.

79.Pandey, A. and M. Mann. 2000. Proteomics to study genes and genomes. Nature 405:837-846.

80.Parekh, R.B. and C. Rohlff. 1997. Post-translational modification of proteins and the discovery of new medicine. Curr. Opin. Biotechnol. 8:718723.

81.Patton, W.F. 2000. A thousand points of light: the application of fluorescence detection technologies to two-dimensional gel electrophoresis and proteomics. Electrophoresis 21:1123-1144. 
82.Paweletz, C.P., L.A. Liotta, and E.F. Petricoin, 3rd. 2001. New technologies for biomarker analysis of prostate cancer progression: laser capture microdissection and tissue proteomics. Urology 57:160-163.

83.Pawlak, M., E. Schick, M.A. Bopp, M.J. Schneider, P. Oroszlan, and M. Ehrat. 2002. Zeptosens' protein microarrays: a novel high performance microarray platform for low abundance protein analysis. Proteomics 2:383393.

84.Piehler, J., A. Brecht, R. Valiokas, B. Liedberg, and G. Gauglitz. 2000. A high-density poly(ethylene glycol) polymer brush for immobilization on glass-type surfaces. Biosens. Bioelectron. 15:473-481.

85.Roberts, R.W. and J.W. Szostak. 1997. RNA-peptide fusions for the in vitro selection of peptides and proteins. Proc. Natl. Acad. Sci. USA 94:12297 12302.

86.Robinson, W.H., C. DiGennaro, W. Hueber, B.B. Haab, M. Kamachi, E.J. Dean, S. Fournel, D. Fong, et al. 2002. Autoantigen microarray for multiplex characterization of autoantibody responses. Nat. Med. 8:295301.

87.Routh, V.H. and C.J. Helke. 1997. A novel technique for producing antibody-coated microprobes using a thiol-terminal silane and a heterobifunctional crosslinker. J. Neurosci. Methods 71:163-168.

88.Rowe, C.A., S.B. Scruggs, M.J. Feldstein, J.P. Golden, and F.S. Ligler 1999. An array immunosensor for simultaneous detection of clinical analytes. Anal. Chem. 71:433-439.

89.Sblattero, D. and A. Bradbury. 2000. Exploiting recombination in single bacteria to make large phage antibody libraries. Nat. Biotechnol. 18:75-80.

90.Schweitzer, B. and S.F. Kingsmore. 2002. Measuring proteins on microarrays. Curr. Opin. Biotechnol. 13:14-19.

91.Schweitzer, B., S. Roberts, B. Grimwade, W. Shao, M. Wang, Q. Fu, Q. Shu, I. Laroche, et al. 2002. Multiplexed protein profiling on microarrays by rolling-circle amplification. Nat. Biotechnol. 20:359-365.

92.Schweitzer, B., S. Wiltshire, J. Lambert, S. O'Malley, K. Kukanskis, Z Zhu, S.F. Kingsmore, P.M. Lizardi, and D.C. Ward. 2000. Inaugural article: immunoassays with rolling circle DNA amplification: a versatile platform for ultrasensitive antigen detection. Proc. Natl. Acad. Sci. USA 97:10113-10119.

93.Service, R.F. 2001. Proteomics. Searching for recipes for protein chips. Science 294:2080-2082.

94.Shriver-Lake, L.C., B. Donner, R. Edelstein, K. Breslin, S.K. Bhatia, and F.S. Ligler. 1997. Antibody immobilization using heterobifunctional crosslinkers. Biosens. Bioelectron. 12:1101-1106.

95.Siegel, D.L. 2002. Recombinant monoclonal antibody technology. Transfus. Clin. Biol. 9:15-22

96.Silzel, J.W., B. Cercek, C. Dodson, T. Tsay, and R.J. Obremski. 1998 Mass-sensing, multianalyte microarray immunoassay with imaging detection. Clin. Chem. 44:2036-2043.

97.Smith, R.D. 2000. Probing proteomes—seeing the whole picture? Nat. Biotechnol. 18:1041-1042.

98.Soderlind, E., M. Ohlin, and R. Carlsson. 1999. Complementarity-determining region (CDR) implantation: a theme of recombination. Immunotechnology 4:279-285.

99.Soderlind, E., L. Strandberg, P. Jirholt, N. Kobayashi, V. Alexeiva, A.M. Aberg, A. Nilsson, B. Jansson, et al. 2000. Recombining germline-derived CDR sequences for creating diverse single-framework antibody libraries. Nat. Biotechnol. 18:852-856.

100.Sreekumar, A., M.K. Nyati, S. Varambally, T.R. Barrette, D. Ghosh, T.S. Lawrence, and A.M. Chinnaiyan. 2001. Profiling of cancer cells using protein microarrays: discovery of novel radiation-regulated proteins. Cancer Res. 61:7585-7593.

101.Templin, M.F., D. Stoll, M. Schrenk, P.C. Traub, C.F. Vohringer, and T.O. Joos. 2002. Protein microarray technology. Trends Biotechnol. 20:160-166.

102.Turkova, J. 1999. Oriented immobilization of biologically active proteins as a tool for revealing protein interactions and function. J. Chromatogr. B Biomed. Sci. Appl. 722:11-31

103.Uetz, P., L. Giot, G. Cagney, T.A. Mansfield, R.S. Judson, J.R. Knight, D. Lockshon, V. Narayan, et al. 2000. A comprehensive analysis of proteinprotein interactions in Saccharomyces cerevisiae. Nature 403:623-627.

104.Vasiliskov, A.V., E.N. Timofeev, S.A. Surzhikov, A.L. Drobyshev, V.V. Shick, and A.D. Mirzabekov. 1999. Fabrication of microarray of gel-immobilized compounds on a chip by copolymerization. BioTechniques 27:592-600.

105.Venter, J.C., M.D. Adams, E.W. Myers, P.W. Li, R.J. Mural, G.G. Sutton,
H.O. Smith, M. Yandell, et al. 2001. The sequence of the human genome. Science 291:1304-1351.

106. Walter, G., K. Bussow, D. Cahill, A. Lueking, and H. Lehrach. 2000. Protein arrays for gene expression and molecular interaction screening. Curr. Opin. Microbiol. 3:298-302.

107.Weng, S., K. Gu, P.W. Hammond, P. Lohse, C. Rise, R.W. Wagner, M.C. Wright, and R.G. Kuimelis. 2002. Generating addressable protein microarrays with PROfusion covalent mRNA-protein fusion technology. Proteomics 2:48-57.

108. Wiese, R., Y. Belosludtsev, T. Powdrill, P. Thompson, and M. Hogan. 2001. Simultaneous multianalyte ELISA performed on a microarray platform. Clin. Chem. 47:1451-1457.

109.Wiltshire, S., S. O’Malley, J. Lambert, K. Kukanskis, D. Edgar, S.F. Kingsmore, and B. Schweitzer. 2000. Detection of multiple allergen-specific IgEs on microarrays by immunoassay with rolling circle amplification. Clin. Chem. 46:1990-1993.

110.Zhu, H., M. Bilgin, R. Bangham, D. Hall, A. Casamayor, P. Bertone, N. Lan, R. Jansen, et al. 2001. Global analysis of protein activities using proteome chips. Science 293:2101-2105.

111.Zhu, H., J.F. Klemic, S. Chang, P. Bertone, A. Casamayor, K.G. Klemic, D. Smith, M. Gerstein, M.A. Reed, and M. Snyder. 2000. Analysis of yeast protein kinases using protein chips. Nat. Genet. 26:283-289.

112.Ziauddin, J. and D.M. Sabatini. 2001. Microarrays of cells expressing defined cDNAs. Nature 411:107-110.

\section{Address correspondence to:}

Dr. Wlad Kusnezow

Functional Genome Analysis

Deutsches Krebsforschungszentrum

Im Neuenheimer Feld 506

D-69120 Heidelberg, Germany

e-mail:w.kusnezow@dkfz.de 